\title{
Piezoelectric or Conventional Osteotomy in Rhinoplasty? A Systematic Review and Meta-Analysis of Clinical Outcomes
}

\author{
Alexios Tsikopoulos ${ }^{a}$ Konstantinos Tsikopoulos $^{b} \quad$ Chrysoula Doxani $^{a}$ \\ Eleni Vagdatlic Gabriele Meroni ${ }^{d}$ Charalambos Skoulakis $^{\mathrm{e}}$ \\ Ioannis Stefanidis ${ }^{f} \quad$ Elias Zintzaras ${ }^{a}$ \\ aLaboratory of Biomathematics, School of Medicine, University of Thessaly, Larissa, Greece; \\ b424 Army General Training Hospital, Thessaloniki, Greece; ' ${ }^{\mathrm{b}}$ Microbiology Department, \\ Hippokration General Hospital, Thessaloniki, Greece; ${ }^{d}$ Department of Biomedical Sciences \\ for Health, University of Milan, Milan, Italy; ${ }^{e}$ Department of Otorhinolaryngology, School \\ of Medicine, University of Thessaly, Larissa, Greece; ${ }^{f}$ Department of Nephrology, School of \\ Medicine, University of Thessaly, Larissa, Greece
}

\section{Keywords}

Rhinoplasty · Osteotomy · Piezosurgery · Edema · Ecchymosis · Pain · Systematic review · Meta-analysis

\begin{abstract}
Introduction: Osteotomy of nasal bones in rhinoplasty is associated with postsurgical morbidities. Recent evidence has suggested that a surgical method applying piezoelectric ultrasound waves for nasal osteotomies in rhinoplasty reduces soft tissue damage and causes less postsurgical morbidities compared to conventional methods. The purpose of this study is to compare clinical outcomes of piezoelectric and conventional lateral nasal osteotomies in rhinoplasty. Methods: We searched PubMed, CENTRAL, and Web of Science up to 17 August 2019 for studies comparing postoperative outcomes of piezoelectric and conventional lateral osteotomies in rhinoplasty. We included studies comparing results of patients subjected to piezoelectric or conventional lateral nasal osteotomies in rhinoplasty. For outcomes, we considered postoperative pain, eyelid edema, periorbital ecchymosis, and intraoperative mucosal injury. Results: For eyelid edema, a statistically significant difference in favor of piezoelectric osteotomy was documented within the first 3 postoperative days (standardized mean difference $[\mathrm{SMD}]=-0.65 ; 95 \% \mathrm{Cl}=-1.18,-0.12, p=0.02 ; R^{2}=69 \%$ ) and on postoperative day 7 $\left(\mathrm{SMD}=-0.69 ; 95 \% \mathrm{Cl}=-1.47,-0.09 ; p=0.08 ; \ell^{2}=85 \%\right)$. This was also the case for periorbital ecchymosis within the first 3 postoperative days $(\mathrm{SMD}=-0.85 ; 95 \% \mathrm{Cl}=-1.42,-0.28 ; p=$ $\left.0.004 ; l^{2}=72 \%\right)$ and on postoperative day $7(\mathrm{SMD}=-0.52 ; 95 \% \mathrm{Cl}=-0.79,-0.24 ; p=0.0003$;
\end{abstract}


$\left.R^{2}=71 \%\right)$. Intraoperative mucosal injury (OR $\left.=0.06 ; 95 \% \mathrm{Cl}=0.01,0.53 ; p=0.01 ; R^{2}=0 \%\right)$ and postoperative pain $\left(\mathrm{SMD}=-0.99 ; 95 \% \mathrm{Cl}=-1.78,-0.11 ; p=0.01 ; R^{2}=49 \%\right)$ were also statistically lower during piezoelectric osteotomies. Conclusions: This study shows that lateral piezoelectric osteotomy in rhinoplasty decreases postoperative pain, edema, ecchymosis, and intraoperative mucosa injuries compared to the conventional osteotomy technique with a chisel. Piezoelectric osteotomies are especially associated with less postoperative edema and ecchymosis in osteotomies not executed under direct vision.

(c) 2020 S. Karger AG, Base

\section{Introduction}

Osteotomy of the nasal bones is the most challenging and critical step in rhinoplasty. The shaping of the nasal bony structures is the key for a successful operation [1]. The type of osteotomy (i.e., medial, lateral, or transverse) depends on the nasal deformity to be addressed in order to achieve the desired esthetic and functional outcome [2]. Lateral osteotomy in particular is the last step of rhinoplasty, and its precision is the key to its success. The main indications for lateral osteotomy include open roof deformity correction after removing the nose hump, narrowing of the nasal pyramid, and straightening the nasal bones [3]. In this phase, the mobilization of nasal bones along with minimizing the damage of supporting tissue and avoiding the excessive narrowing are the main goals of lateral osteotomy [4]. Various techniques for lateral osteotomies have been described for the desired aesthetic and functional results, with reduction of soft tissue damage during rhinoplasty as the major goal. There is still ambiguity regarding the optimal one [5]. Apart from surgical approaches, various different techniques and methods, including percutaneous, trans-oral and endo-nasal procedures, have been suggested to make this step less traumatic by reducing soft tissue damage during osteotomies [6,7]. Each technique has both advantages and limitations. Soft-tissue trauma in particular may lead to prolonged postoperative edema and ecchymosis, as well as apparent irregularities in nasal bone owing to the thin overlying skin. Therefore, a precise and safe osteotomy technique is the desideratum for the preservation of bony structures and protection of adjacent soft tissues [8].

Piezoelectric surgery is a new method commonly used during osteotomies, which takes advantage of ultrasonic piezoelectric vibrations in order to decrease the severity of morbidities [9]. Its ability to minimize tissue trauma and its associated morbidity, along with its cutting effectiveness, has rendered piezosurgery popular for several clinical applications in various surgical fields during the last decades [10]. This method is considered a relatively new alternative for bony procedures in craniofacial surgeries [11]. It was first introduced by Horton et al. [12] in alveolar bone surgery in 1975. Since then, the technique has improved rapidly, and its indications have been extended as well [13]. Robiony et al. [8] was the first to describe nasal osteotomy using piezoelectric devices, achieved by adjusting the power and frequency of ultrasound waves employed. Since then, several studies have been conducted indicating that piezoelectric instruments are connected with fewer morbidities in both external and internal lateral osteotomies. This instrument allows precision in osteotomies, thus minimizing damage of surrounding soft tissues and critical structures (nerves, vessels, and mucosa), and avoiding osteonecrosis [14].

Although several studies have compared the difference in postsurgical morbidities between piezoelectric and conventional osteotomy, none of them have reached a clear conclusion regarding the superiority of either method [15-21]. In the vast majority of those studies, sample size was limited, and therefore reliable conclusions on which of the two methods is more effective in reducing edema and ecchymosis could not be drawn. 


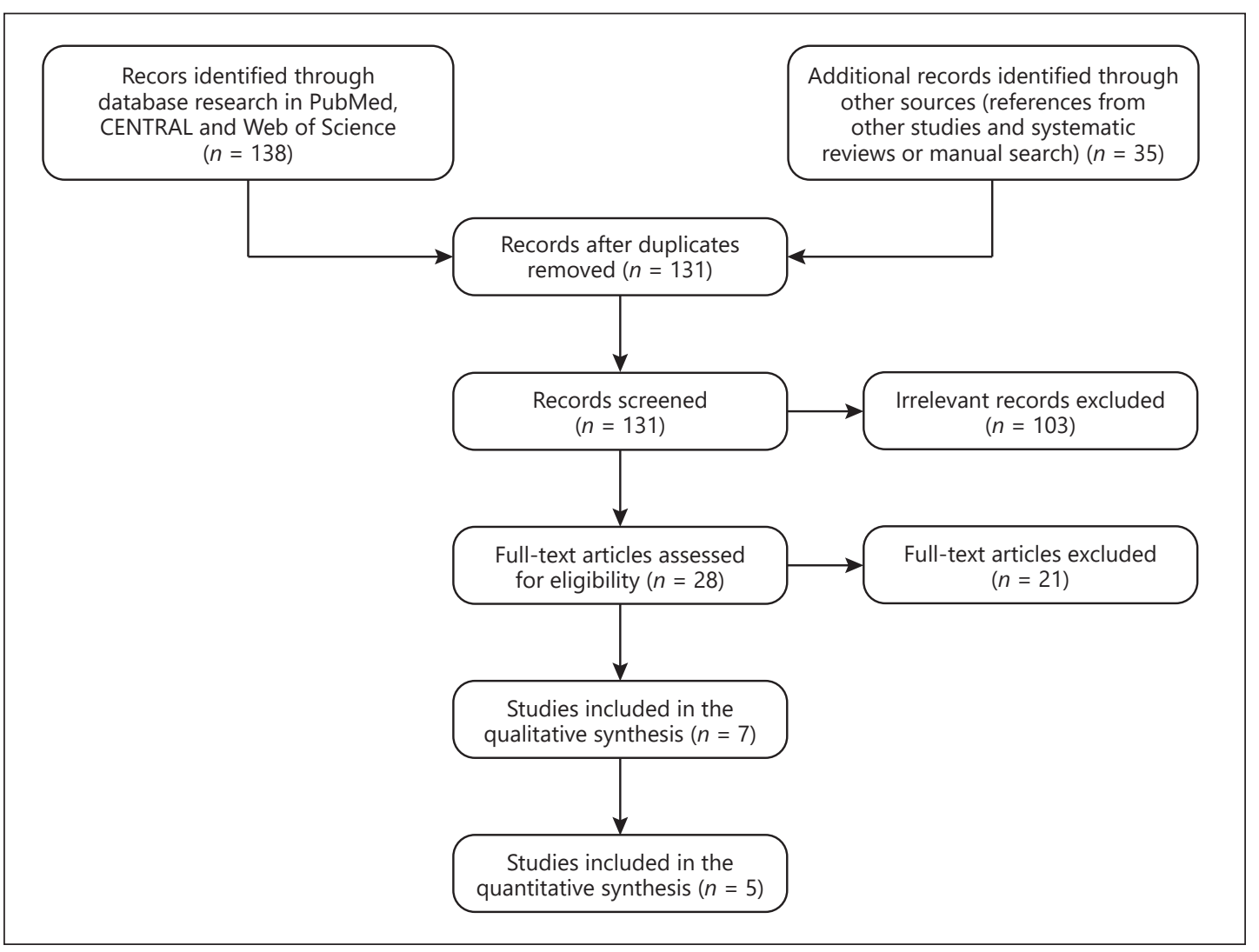

Fig. 1. Flow diagram of the study selection procedure.

In the current meta-analysis, we sought to compare and analyze the main intraoperative and postoperative outcomes of piezoelectric and conventional osteotomy in lateral nasal osteotomies in rhinoplasty, by synthesizing evidence from randomized controlled trials (RCTs) that compared these two techniques. Our initial aim was to compare the results between those surgical methods in order to prove possible superiority of one of them.

\section{Methods}

We used the Preferred Reporting Items for Systematic Reviews and Meta-Analyses (PRISMA).

\section{Inclusion and Exclusion Criteria}

In this meta-analysis, were included only randomized clinical trials investigating the intraoperative and postoperative morbidities of lateral osteotomy in rhinoplasty using either a piezoelectric device or a conventional osteotome. We chose studies in which the patients were subjected to lateral nasal osteotomies during rhinoplasty (open or closed), either with a conventional osteotome (control group) or with an ultrasonic piezoelectric device (intervention group). The comparison of the piezoelectric with the conventional osteotomy applied to either intraoperative morbidities (mucosal injury) or postoperative morbidities (eyelid edema, periorbital ecchymosis, and postoperative pain). We excluded trials which studied the effects of piezoelectric osteotomy on different surgical procedures or trials which did not present quantifiable data.

Literature Search

We performed a literature search including the following electronic databases from 2005 up to 17 August 2019: PubMed, Cochrane Central Register of Controlled Trials (CENTRAL), and Web of Science. In 
Tsikopoulos et al.: Piezoelectric or Conventional Osteotomy in Rhinoplasty?

\begin{tabular}{|c|c|c|c|c|c|c|c|c|c|c|c|}
\hline \multirow{4}{*}{$\begin{array}{l}\text { Study or subgroup } \\
\text { Kocak, } 2017 \\
\text { Tirelli, } 2015\end{array}$} & \multicolumn{2}{|l|}{ Piezo } & \multicolumn{2}{|c|}{ Conventional } & \multirow{3}{*}{$\begin{array}{l}\begin{array}{l}\text { Weight, } \\
\%\end{array} \\
51.6\end{array}$} & \multirow{3}{*}{$\begin{array}{l}\text { Odds ratio, } \mathrm{M}-\mathrm{H}, \\
\text { random, } 95 \% \mathrm{Cl}\end{array}$} & \multirow{2}{*}{\multicolumn{5}{|c|}{$\begin{array}{l}\text { Odds ratio } \mathrm{M}-\mathrm{H}, \\
\text { random, } 95 \% \mathrm{Cl}\end{array}$}} \\
\hline & \multirow{3}{*}{$\begin{array}{l}\text { events } \\
0 \\
0\end{array}$} & \multirow{2}{*}{$\frac{\text { total }}{24}$} & \multirow{2}{*}{$\frac{\text { events }}{5}$} & \multirow{2}{*}{$\frac{\text { total }}{25}$} & & & & & & & \\
\hline & & & & & & & & $\longrightarrow$ & - & & \\
\hline & & 11 & 5 & 11 & 48.4 & $0.05(0.00,1.09)$ & & - & & & \\
\hline Total $(95 \% \mathrm{Cl})$ & & 35 & & 36 & 100.0 & $0.06(0.01,0.53)$ & & & & & \\
\hline \multirow{2}{*}{\multicolumn{6}{|c|}{$\begin{array}{l}\text { Heterogeneity: } \tau^{2}=0.00 ; \chi^{2}=0.03, \mathrm{df}=1(p=0.86) ; I^{2}=0 \% \\
\text { Test for overall effect: } Z=2.55(p=0.01)\end{array}$}} & & 0.01 & 0.1 & 1 & 10 & 100 \\
\hline & & & & & & & & $\begin{array}{c}\text { Favors } \\
\text { (experimental) }\end{array}$ & & $\begin{array}{l}\text { Favors } \\
\text { (control) }\end{array}$ & \\
\hline
\end{tabular}

Fig. 2. Forest plot of standardized mean differences for the assessment of intraoperative mucosal injury.

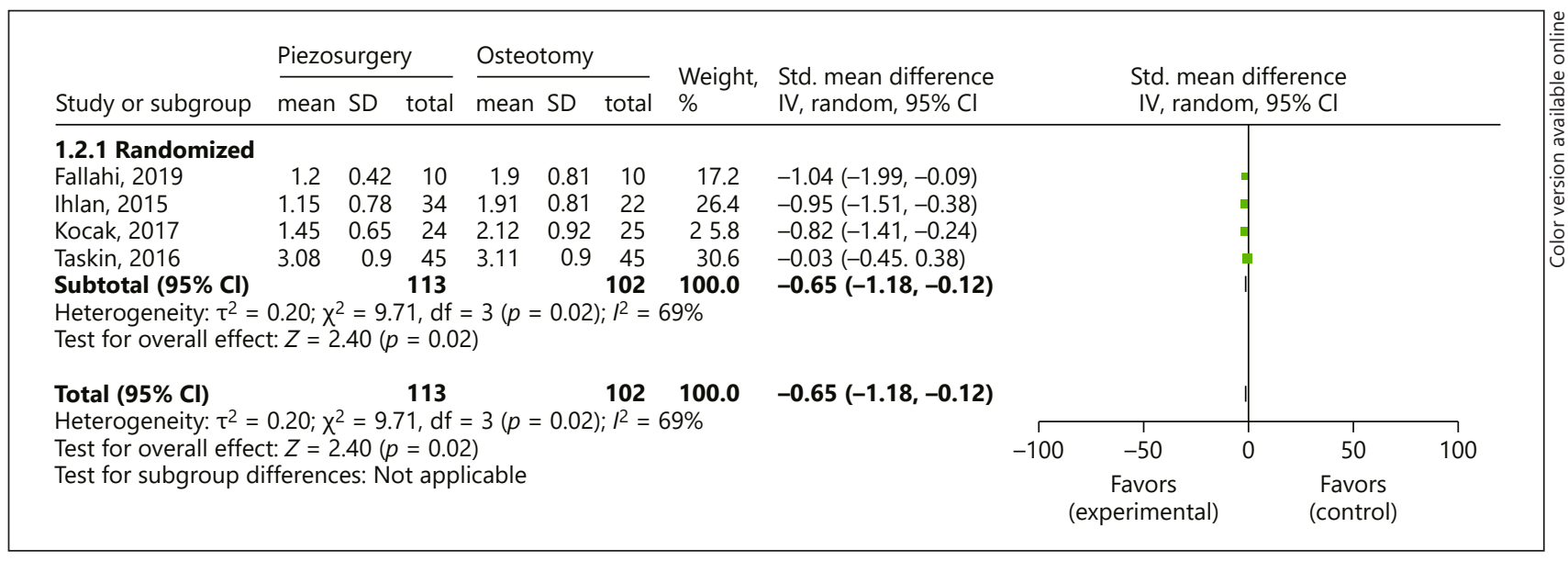

Fig. 3. Forest plot of standardized mean differences for the assessment of eyelid edema within the first 3 postoperative days.

these database searches, we applied no language restrictions. We also considered reference lists of relevant studies. Furthermore, we searched ClinicalTrials.gov for completed unpublished comparative studies. This search was conducted using Preferred Reporting Items for Systematic Reviews and Meta-Analysis (PRISMA) guidelines. For the search strategy we used the following terms: "piezosurgery," "piezoelectric," "rhinoplasty," "osteotomy." We adapted this search to each included database.

\section{Study Selection}

The titles and abstracts of these records were screened for eligibility. For the eligible articles, we obtained the full texts and assessed them for potential inclusion. We included only RCTs in the meta-analysis. Totally, we retrieved 138 articles (59 articles from Web of Science, 28 articles from PubMed, 14 articles from CENTRAL, and 37 from clinicaltrials.gov). Additionally, we reached another 35 articles from other sources such as references from other studies and systematic reviews. Duplicate studies were removed, and 131 articles were left for assessment. The initial screening discarded studies that were not related to piezoelectric osteotomy in rhinoplasty. Totally, 28 articles were topic relevant. Full-text articles were obtained for all potentially relevant studies. Out of them, only 7 were randomized and used controlled groups to assess the effect of piezoelectric osteotomy in rhinoplasty with quantifiable data. Figure 1 depicts the strategy used for study identification.

\section{Data Extraction}

We recorded the following data: year of publication, comparators in the control group as well as number and demographics of patients in the included intervention groups. We also extracted information about intervention characteristics, follow-up, and study outcomes (Fig. 2 and 3). In particular, we assessed intra- 
Tsikopoulos et al.: Piezoelectric or Conventional Osteotomy in Rhinoplasty?

operative morbidities (mucosal injury) as well as postsurgical morbidities such as eyelid edema and periorbital ecchymosis (within 3 days or on day 7 postoperatively) and postoperative pain (within 3 days postoperatively). Eyelid edema and periorbital ecchymosis were evaluated separately using graded scales. Postoperative pain was assessed with a pain score. More specifically, assessment of the outcomes was conducted as follows:

- Mucosa injury: Patients were subjected to endoscopic examination on day 4 postoperatively.

- Pain: Postoperative pain was assessed by visual analogue scale (VAS). A ten-point scale was applied, in which zero represented the absence of pain whereas 10 represented the most severe pain.

- Edema: Eyelid edema was evaluated by a 4-grade visual scale [22]. Grade 1 represented no coverage of iris with eyelids, grade 2 slight coverage of iris with swollen eyelids, grade 3 full coverage of iris with swollen eyelids, and grade 4, full coverage of the eye [22].

- Ecchymosis: Eyelid ecchymosis was assessed by a 3-grade visual scale [22]. Grade 1 represented ecchymosis up to the medial one-third part of the lower and/or the upper eyelid, grade 2 ecchymosis up to the medial two-third part of the lower and/or the upper eyelid and grade 3 , ecchymosis up to the full length and/or the upper eyelid [22].

\section{Quality Assessment}

Quality assessment of individual trials was performed using the Cochrane Collaboration's "risk bias" tool [23]. In particular, the following domains were considered: randomization; allocation concealment, blinding of patients, blinding of personnel and blinding of outcome assessors. We judged each domain as either low, unclear, or high risk of bias. Furthermore, we assessed the quality across studies. For each domain of the Cochrane's risk of bias tool, if more than half of the information was from studies at a low risk of bias, we judged the domain to be at a low risk of bias. If most information was from studies at an unclear/high risk of bias, we considered the domain to be an unclear/high risk of bias, respectively.

\section{Statistical Analysis}

We used the Review Manager (RevMan) Software (version 5.3) to perform pairwise meta-analysis. For continuous outcomes, we conducted random effects quantitative synthesis utilizing the effect size of standardized mean difference (SMD) and calculated 95\% confidence intervals (CIs) according to the inverse variance method. For dichotomous outcomes, we conducted a random effects meta-analysis using the Mantel-Haenszel method and considered the effect measure of odds ratio (OR). In this review, a $p$ value of less than 0.05 indicated statistical significance. We explored for statistical heterogeneity using the $Q$ statistic and measured the extent of heterogeneity using the $I^{2}$ statistic.

We considered the following classification of statistical heterogeneity [24]:

- $\quad I^{2}=0-40 \%$ : not important heterogeneity;

- $\quad I^{2}=30-60 \%$ : moderate heterogeneity;

- $\quad I^{2}=50-90 \%$ : substantial heterogeneity;

- $\quad I^{2}=75-100 \%$ : considerable heterogeneity.

We avoided using funnel plot for publication bias detection, because in our analysis, we included only 5 studies. When there are fewer than 10 studies, the power of those tests is too low to distinguish chance from real asymmetry [25].

\section{Subgroup and Sensitivity Analyses}

We accounted for the impact of the osteotomy visibility (that is blind osteotomy vs. osteotomy under direct vision), depending on the width of the incision performed ( $3 \mathrm{~mm}$ or lower) by conducting a prespecified subgroup analysis. Furthermore, we performed a sensitivity analysis, in which we excluded trials of an unclear and high risk of bias.

Clinical Interpretation of the Results

The classification of the effect sizes in the meta-analysis was as follows [26]:

- $\quad$ SMD <0.4: small effect;

- $\quad 0<$ SMD < 0.7 : moderate effect;

- $\quad 0.7<$ SMD: large effect.

For the clinical interpretation of the results, we accounted for the level of evidence and statistical power of the analysis. 
Tsikopoulos et al.: Piezoelectric or Conventional Osteotomy in Rhinoplasty?

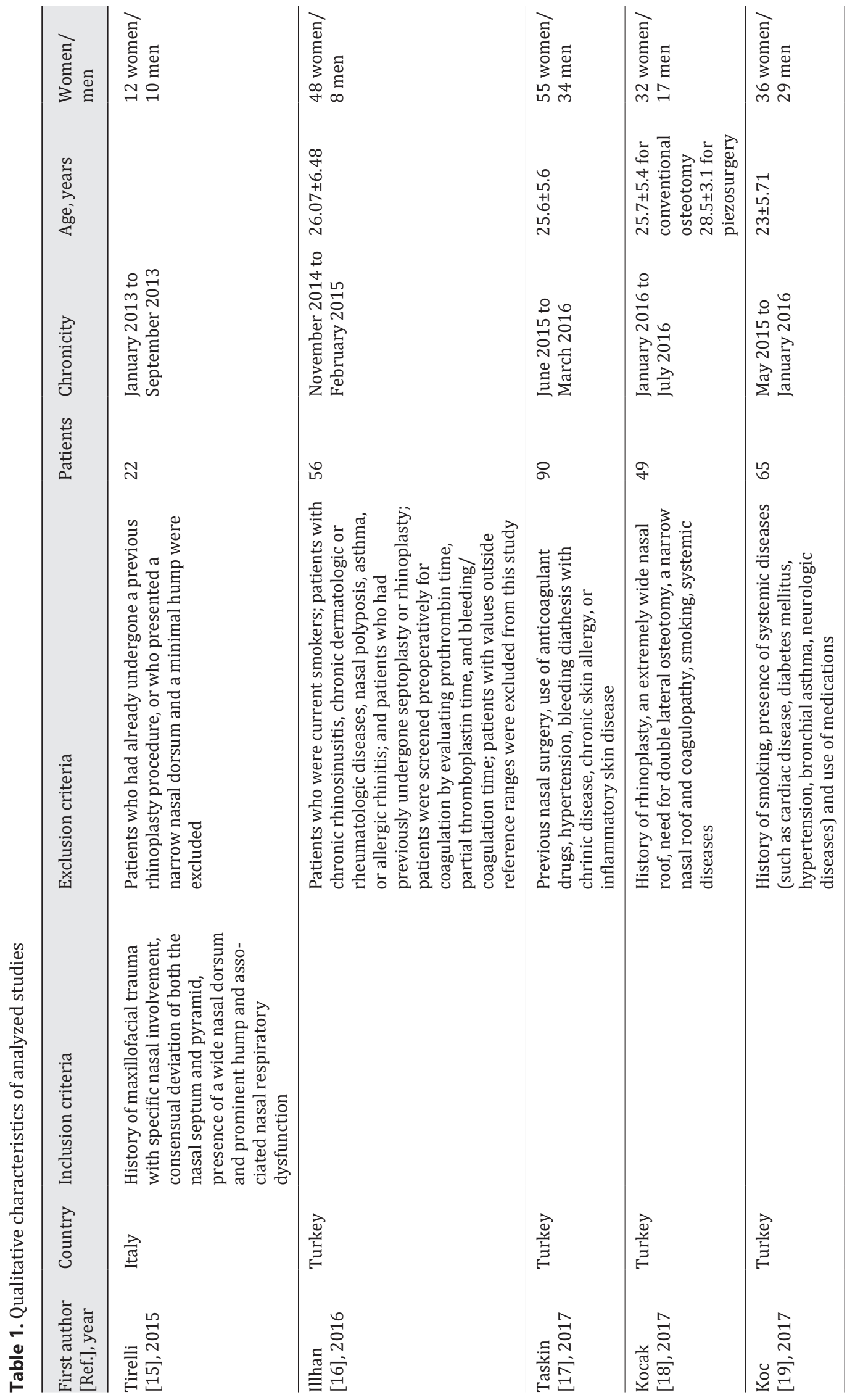




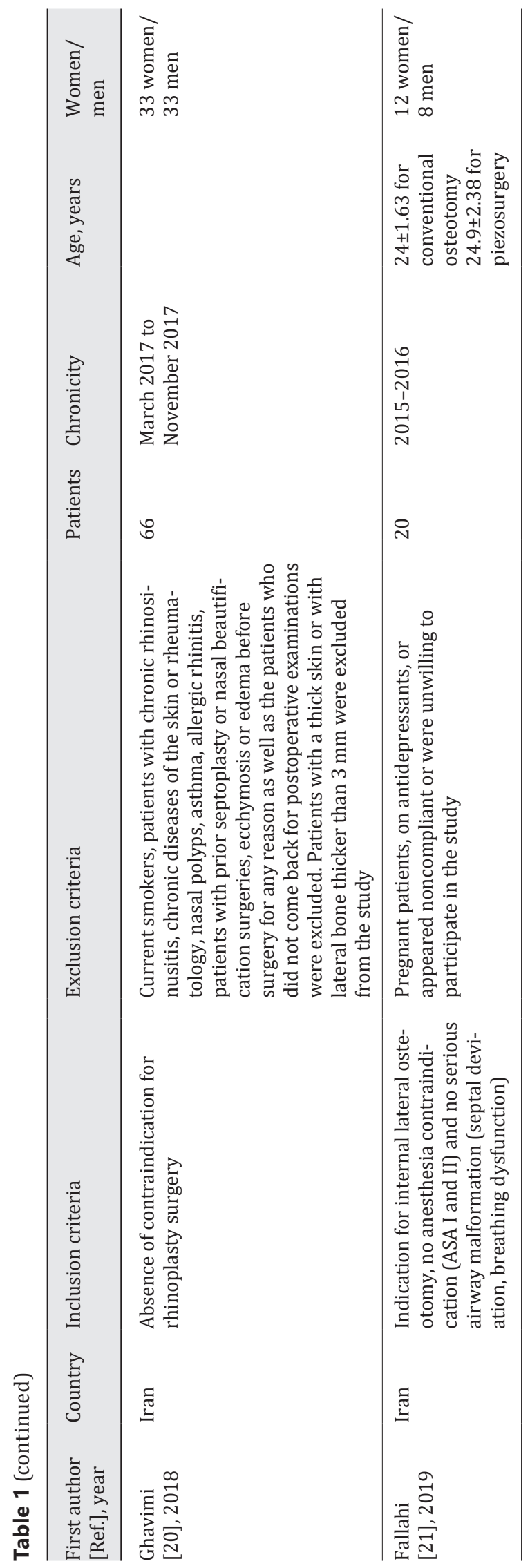


Table 2. Qualitative characteristics of analyzed studies

\begin{tabular}{|c|c|c|c|c|}
\hline $\begin{array}{l}\text { First author } \\
\text { [Ref.], year }\end{array}$ & Outcome measure & Surgical technique, control group & $\begin{array}{l}\text { Surgical technique, } \\
\text { intervention group }\end{array}$ & $\begin{array}{l}\text { Osteotomy } \\
\text { approach/soft tissue } \\
\text { dissection }\end{array}$ \\
\hline $\begin{array}{l}\text { Tirelli } \\
{[15], 2015}\end{array}$ & $\begin{array}{l}\text { Eyelid edema, periorbital } \\
\text { ecchymosis, operative time, } \\
\text { mucosal injury }\end{array}$ & $\begin{array}{l}\text { Lateral osteotomy with conven- } \\
\text { tional 3-mm, guided, curved oste- } \\
\text { otome }\end{array}$ & $\begin{array}{l}\text { Lateral osteotomy with Vario- } \\
\text { Surg-3-piezo-instrument }\end{array}$ & $\begin{array}{l}\text { External approach/ } \\
\text { limited dissection }\end{array}$ \\
\hline $\begin{array}{l}\text { Illhan } \\
\text { [16], } 2016\end{array}$ & $\begin{array}{l}\text { Eyelid edema, periorbital } \\
\text { ecchymosis }\end{array}$ & $\begin{array}{l}\text { Lateral osteotomy with no further } \\
\text { defined conventional instruments }\end{array}$ & $\begin{array}{l}\text { Lateral osteotomy with } \\
\text { micro-saw OT7 tip (Mectron, } \\
\text { Carasco, Italy) piezo-in- } \\
\text { strument }\end{array}$ & $\begin{array}{l}\text { Intranasal approach/ } \\
\text { limited dissection }\end{array}$ \\
\hline $\begin{array}{l}\text { Taskin } \\
{[17], 2017}\end{array}$ & $\begin{array}{l}\text { Eyelid edema, Periorbital } \\
\text { ecchymosis }\end{array}$ & $\begin{array}{l}\text { Osteotomy with no further defined } \\
\text { conventional instruments }\end{array}$ & $\begin{array}{l}\text { Lateral osteotomy with } \\
\text { piezo-instrument }\end{array}$ & $\begin{array}{l}\text { Intranasal approach/ } \\
\text { wide dissection }\end{array}$ \\
\hline $\begin{array}{l}\text { Kocak } \\
{[18], 2017}\end{array}$ & $\begin{array}{l}\text { Eyelid edema, periorbital } \\
\text { ecchymosis, operative time, } \\
\text { pain score, mucosal injury }\end{array}$ & $\begin{array}{l}\text { Osteotomy with conventional } \\
\text { 2-mm, guarded, straight osteotome }\end{array}$ & $\begin{array}{l}\text { Lateral osteotomy with } \\
\text { e piezo-instrument }\end{array}$ & $\begin{array}{l}\text { Intranasal approach/ } \\
\text { limited dissection }\end{array}$ \\
\hline $\begin{array}{l}\text { Koc } \\
{[19], 2017}\end{array}$ & $\begin{array}{l}\text { Eyelid edema, periorbital } \\
\text { ecchymosis, operative time, } \\
\text { pain score }\end{array}$ & $\begin{array}{l}\text { Lateral nasal osteotomy by using } \\
\text { two stab incisions by utilizing a } \\
\text { 2-mm osteotome }\end{array}$ & $\begin{array}{l}\text { Lateral nasal osteotomy after } \\
\text { two stab incisions with } 2 \mathrm{~mm} \\
\text { using the Viosurg device from } \\
\text { NSK Company with a lateral } \\
\text { osteotomy pen }\end{array}$ & $\begin{array}{l}\text { External approach/ } \\
\text { limited dissection }\end{array}$ \\
\hline $\begin{array}{l}\text { Ghavimi } \\
{[20], 2018}\end{array}$ & $\begin{array}{l}\text { Eyelid edema, periorbital } \\
\text { ecchymosis }\end{array}$ & $\begin{array}{l}\text { Lateral osteotomy with external } \\
\text { percutaneous approach with a } \\
\text { 2-mm traditional osteotome }\end{array}$ & $\begin{array}{l}\text { Lateral osteotomy with } \\
\text { external percutaneous } \\
\text { approach with the piezos- } \\
\text { urgery medical device }\end{array}$ & $\begin{array}{l}\text { External approach/ } \\
\text { limited dissection }\end{array}$ \\
\hline $\begin{array}{l}\text { Fallahi } \\
{[21], 2019}\end{array}$ & $\begin{array}{l}\text { Eyelid edema, periorbital } \\
\text { ecchymosis, operative time, } \\
\text { pain score }\end{array}$ & $\begin{array}{l}\text { Lateral osteotomy with a standard } \\
\text { chisel }\end{array}$ & $\begin{array}{l}\text { Lateral osteotomy with } \\
\text { piezo-instrument }\end{array}$ & $\begin{array}{l}\text { Intranasal approach/ } \\
\text { wide dissection }\end{array}$ \\
\hline
\end{tabular}

Table 3. Quality assessment of the included trials

\begin{tabular}{lllllll}
\hline First author [Ref.], year & Randomization & $\begin{array}{l}\text { Allocation } \\
\text { concealment }\end{array}$ & $\begin{array}{l}\text { Blinding of } \\
\text { participants }\end{array}$ & $\begin{array}{l}\text { Blinding of } \\
\text { personnel }\end{array}$ & $\begin{array}{l}\text { Blinding of outcome } \\
\text { assessors }\end{array}$ & $\begin{array}{l}\text { Overall risk of } \\
\text { bias }\end{array}$ \\
\hline $\begin{array}{l}\text { Tirelli [15], 2015 } \\
\text { Ihlan [16], 2016 }\end{array}$ & Low & Unclear & Low & Unclear & Low & Low \\
Taskin [17], 2017 & Unclear & Unclear & Low & Unclear & Low & Low \\
Koçak [18], 2017 & Low & Unclear & Unclear & Unclear & Low & Unclear \\
Koc [19], 2017 & Low & Unclear & Lnclear & Unclear & Low & Unclear \\
Ghavimi [20], 2018 & Unclear & Unclear & Low & Unclear & Low & Low \\
Fallahi [21], 2019 & Low & Low & Low & Low & Low & Unclear \\
\hline
\end{tabular}

\section{Results}

Seven studies with 347 patients were included for qualitative synthesis in this systematic review. Totally, 208 of the participants were women and 139 were men. The qualitative data regarding the participants' age could not be assessed because of incomplete reporting among the studies. The study characteristics are depicted in Tables 1 and 2. Additionally, 5 studies with 246 patients were included for the quantitative synthesis. The extracted data were used for the comparison of intraoperative outcomes (mucosa injury) as well as for the comparison of intraoperative outcomes (eyelid edema, periorbital ecchymosis, postoperative pain). The studies were also assessed for risk of bias (Table 3). 
Tsikopoulos et al.: Piezoelectric or Conventional Osteotomy in Rhinoplasty?

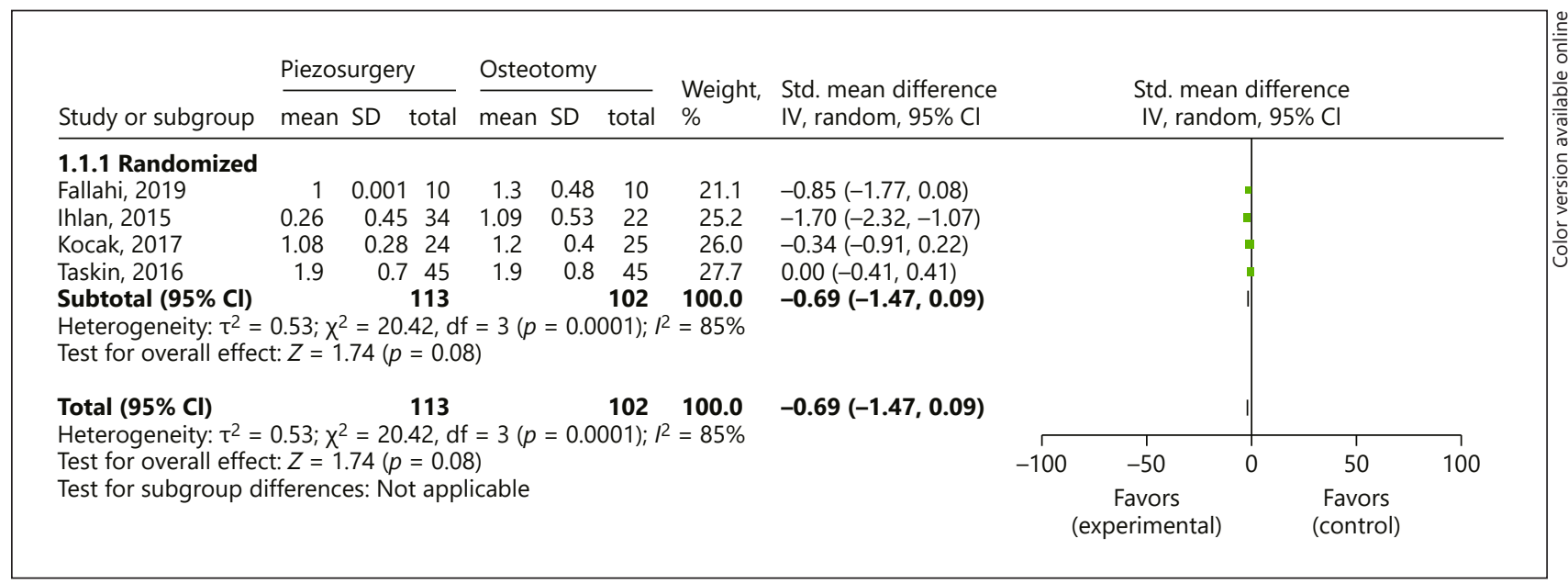

Fig. 4. Forest plot of standardized mean differences for the assessment of eyelid edema on postoperative day 7.

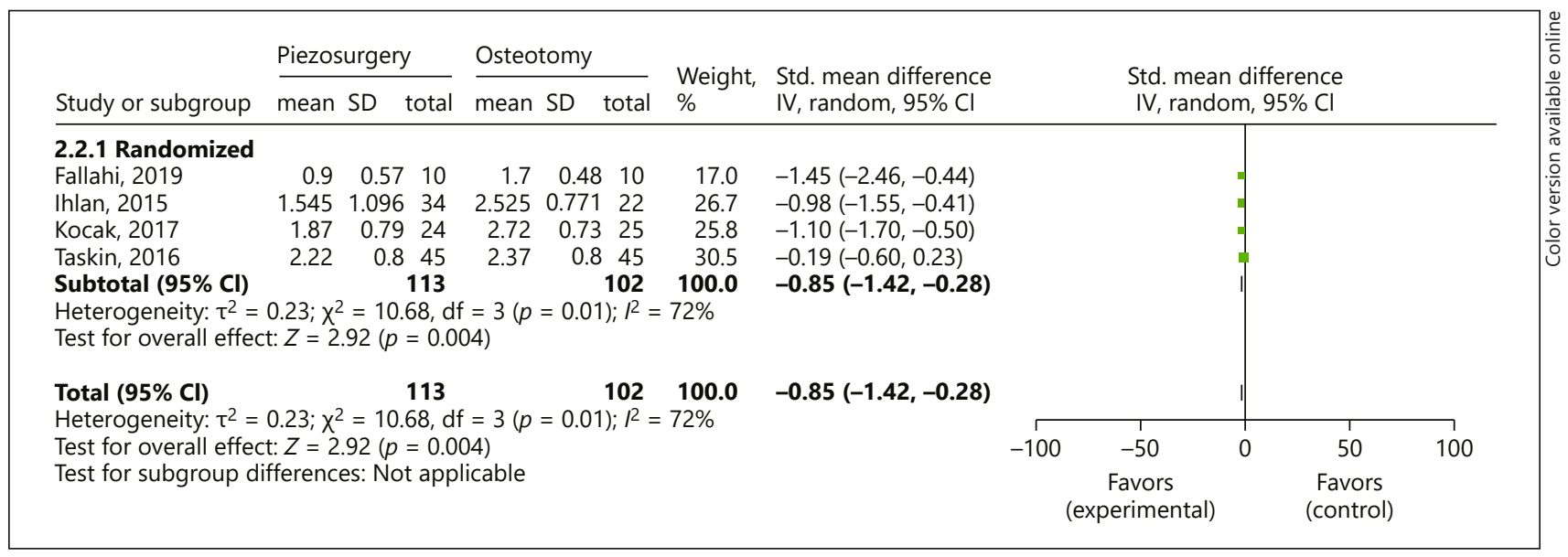

Fig. 5. Forest plot of standardized mean differences for the assessment of periorbital ecchymosis within the first 3 postoperative days.

\section{Intraoperative Outcomes}

Only 2 studies provided data regarding intraoperative mucosa injury, examined by endoscopy on day 4 postsurgically. The incidence of intraoperative mucosal injury $(\mathrm{OR}=0.06$; $95 \% \mathrm{CI}=0.01,0.53 ; p=0.01 ; I^{2}=0 \%$; Fig. 2 ) was statistically lower during the piezoelectric in comparison with the conventional osteotomy. The interstudy heterogeneity was insignificant.

\section{Postoperative Outcomes}

Eyelid edema and periorbital ecchymosis were assessed by the data extracted by 4 studies.

Eyelid edema in particular, was assessed within the first 3 postoperative days (SMD = $-0.65 ; 95 \% \mathrm{CI}=-1.18,-0.12 ; I^{2}=69 \% ; p=0.02$; Fig. 3 ) as well as on postoperative day 7 $\left(\mathrm{SMD}=-0,69 ; 95 \% \mathrm{CI}=-1.47,-0.09 ; p=0.08 ; I^{2}=85 \%\right.$; Fig. 4). Eyelid edema was statistically lower in patients that underwent piezoelectric osteotomies. The difference in eyelid edema was higher between the control and intervention groups on day 7 than within the first 3 postoperative days. Substantial interstudy heterogeneity was found in these outcomes. 
Tsikopoulos et al.: Piezoelectric or Conventional Osteotomy in Rhinoplasty?

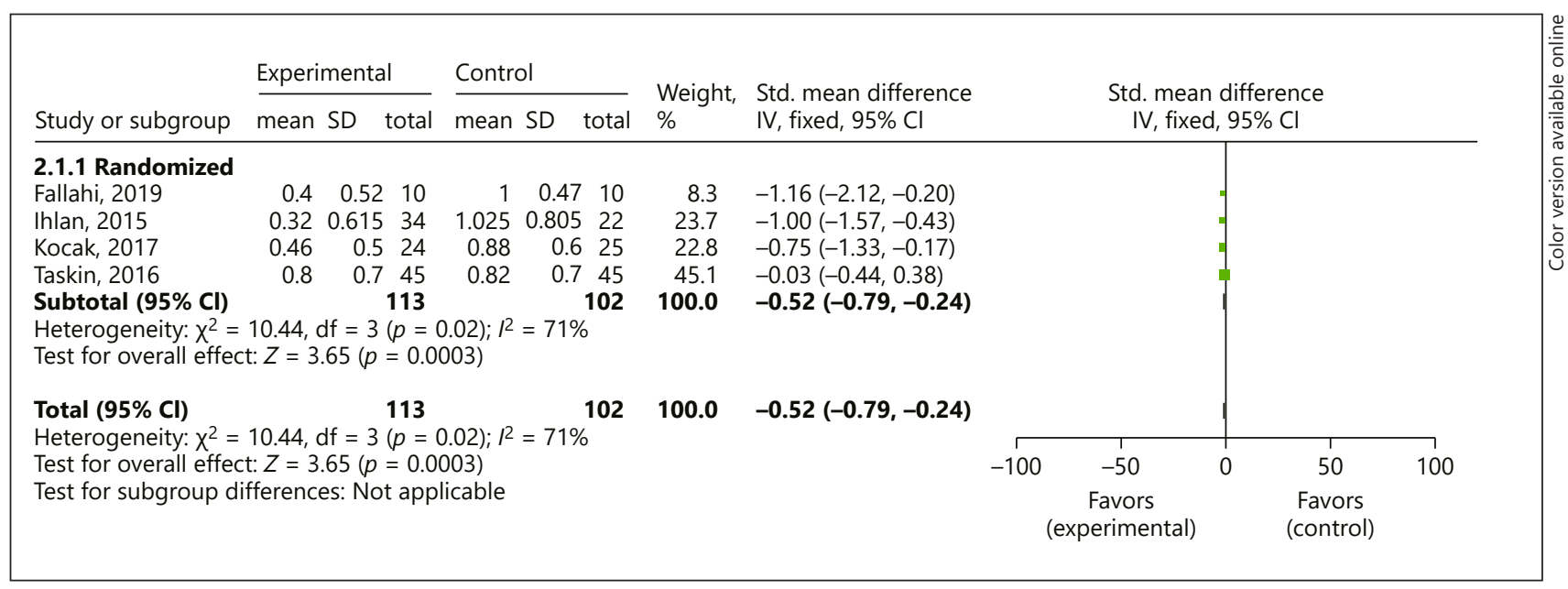

Fig. 6. Forest plot of standardized mean differences for the assessment of periorbital ecchymosis on postoperative day 7.

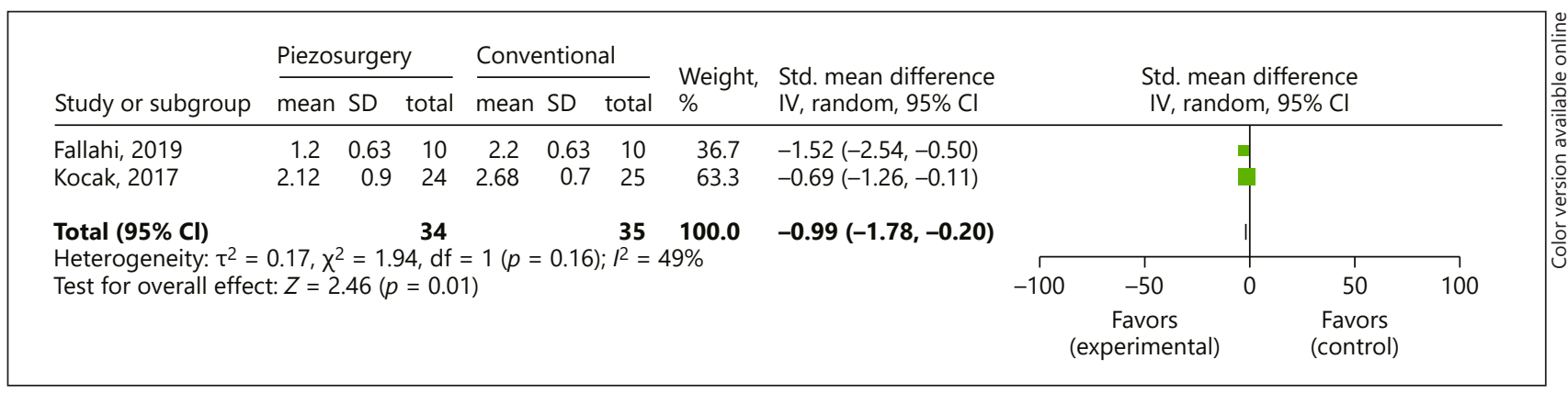

Fig. 7. Forest plot of standardized mean differences for the assessment of postoperative pain within the first 3 postoperative days.

Periorbital ecchymosis was assessed also within the first 3 postoperative days (SMD = $-0.85 ; 95 \% \mathrm{CI}=-1.42,-0.28 ; I^{2}=72 \% ; p=0.004 ;$ Fig. 5 ) as well as on postoperative day 7 $\left(\mathrm{SMD}=-0.52 ; 95 \% \mathrm{CI}=-0.79,-0.24 ; p=0.0003 ; I^{2}=71 \%\right.$; Fig. 6$)$. It is obvious that periorbital ecchymosis is lower in patients that underwent piezoelectric osteotomy. The difference between periorbital ecchymosis was lower between the control and intervention group on day 7 than within the first 3 postoperative days. Substantial interstudy heterogeneity was found in these outcomes.

Postoperative pain within the first 3 days postoperatively, was analyzed using the available data from 2 studies. (SMD $=-0.99 ; \mathrm{CI}=-1.78,-0.11 ; I^{2}=49 \% ; p=0.01 ;$ Fig. 7 ). The postoperative pain was lower in the patients that underwent piezoelectric osteotomy in comparison with those that underwent conventional osteotomy. Moderate heterogeneity was found in this outcome.

\section{Subgroup Analysis}

Substantial heterogeneity was found in both outcomes (eyelid edema and periorbital ecchymosis). In all these RCTs, the same surgical approach was performed (internal lateral osteotomy). However, surgical approach defined the extent of incision performed. A wide surgical incision ( $3 \mathrm{~mm}$ ), and thus lateral osteotomy under vision, was performed only in 2 of the analyzed clinical trials. In contrast, a narrow surgical incision was preferred in the 


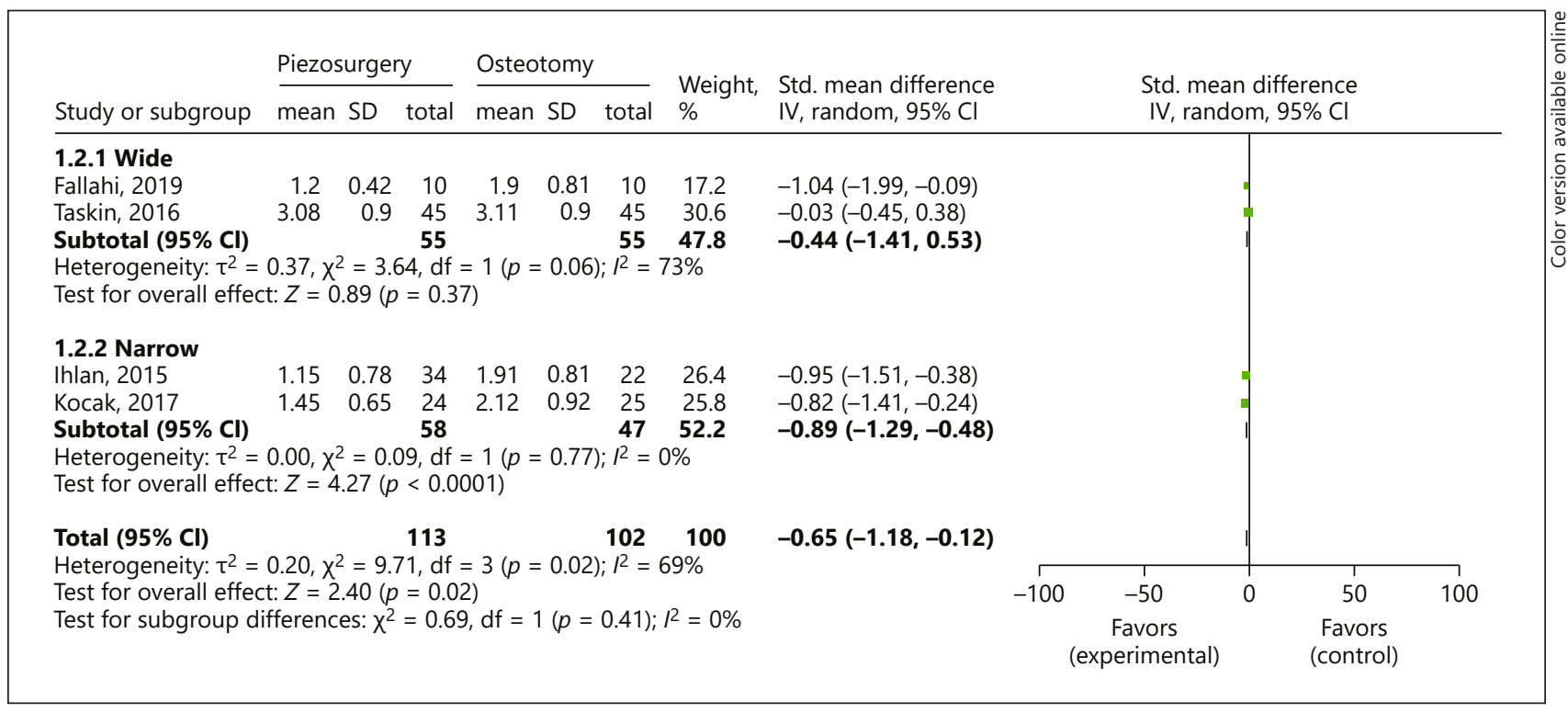

Fig. 8. Forest plot of standardized mean differences for the assessment of eyelid edema within the first 3 postoperative days considering the width of surgical incision.

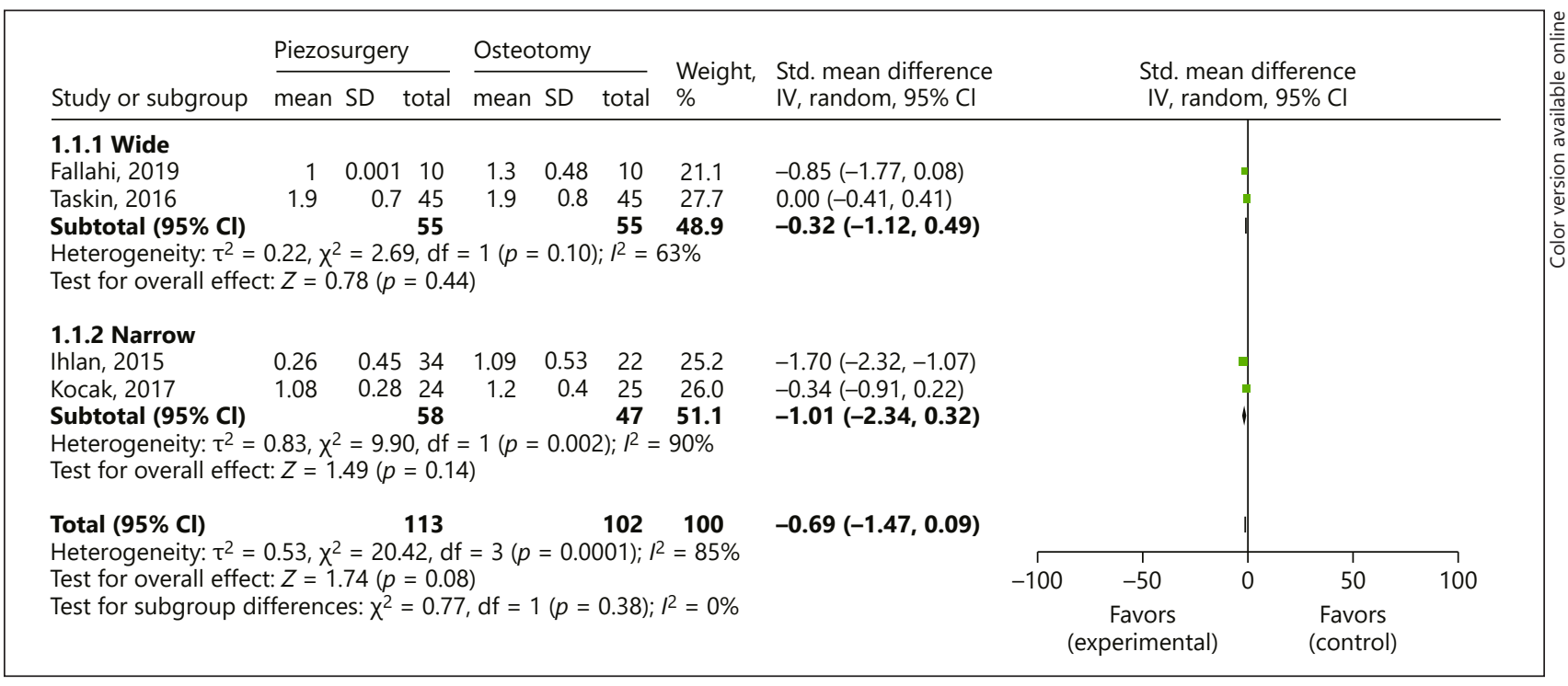

Fig. 9. Forest plot of standardized mean differences for the assessment of eyelid edema on postoperative day 7 considering the width of surgical incision.

remaining studies, and the osteotomy was executed blindly. Thus, a subgroup analysis was performed dividing the studies based on the width of the surgical incision.

Overall, both postsurgical eyelid edema and periorbital ecchymosis were statistically lower in patients that underwent lateral osteotomies under direct vision (Fig. 8-11). However, piezoelectric osteotomy under direct vision had no significant difference in edema and ecchymosis compared to conventional osteotomy, especially on the postoperative day 7 .

Eyelid edema was assessed within the first 3 postoperative days separately for patients that underwent lateral osteotomy with a wide surgical incision $(\mathrm{SMD}=-0.44 ; \mathrm{CI}=-1.41$, $-0.53 ; I^{2}=73 \% ; p=0.37$; Fig. 8 ) as well as for those who underwent a narrow surgical incision 
Tsikopoulos et al.: Piezoelectric or Conventional Osteotomy in Rhinoplasty?

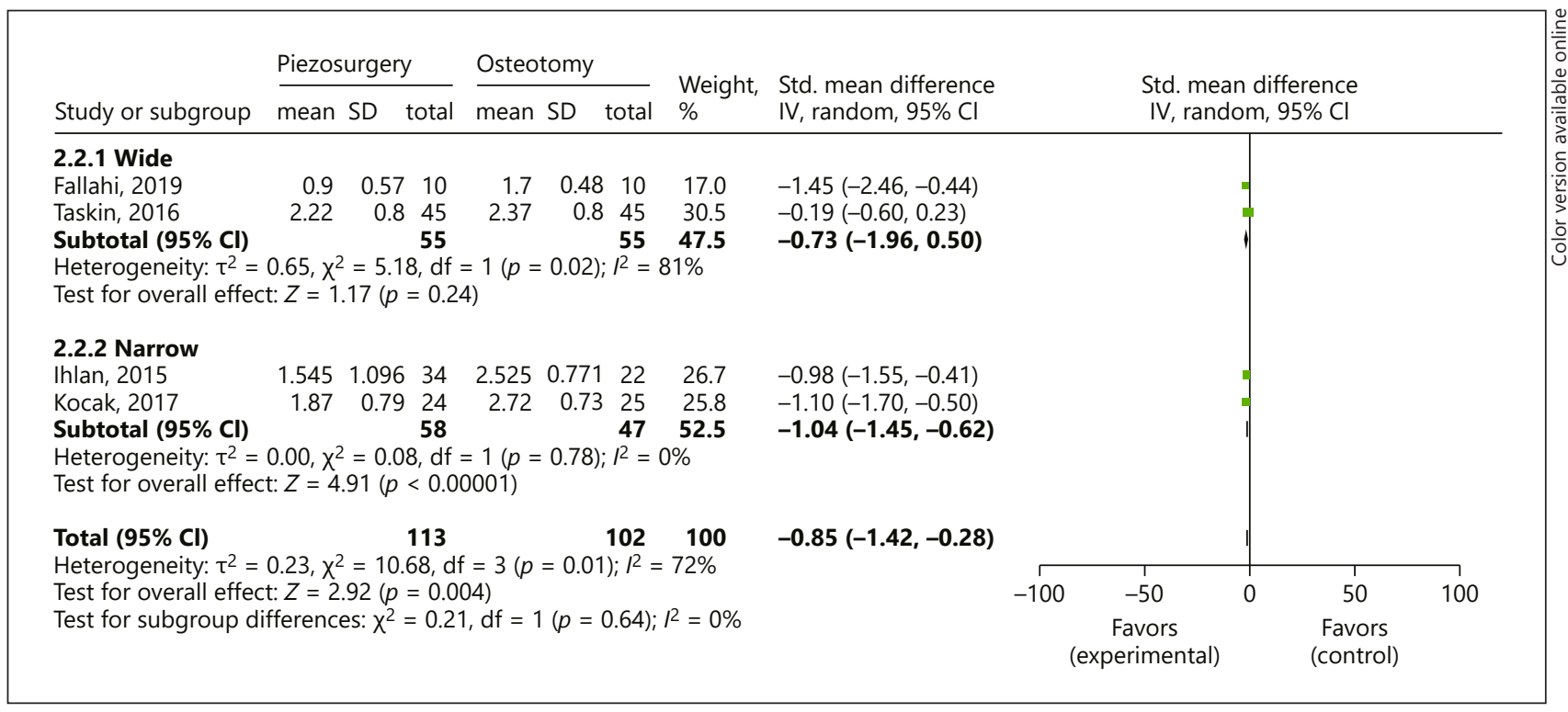

Fig. 10. Forest plot of standardized mean differences for the assessment of periorbital ecchymosis within the first 3 postoperative days considering the width of surgical incision.

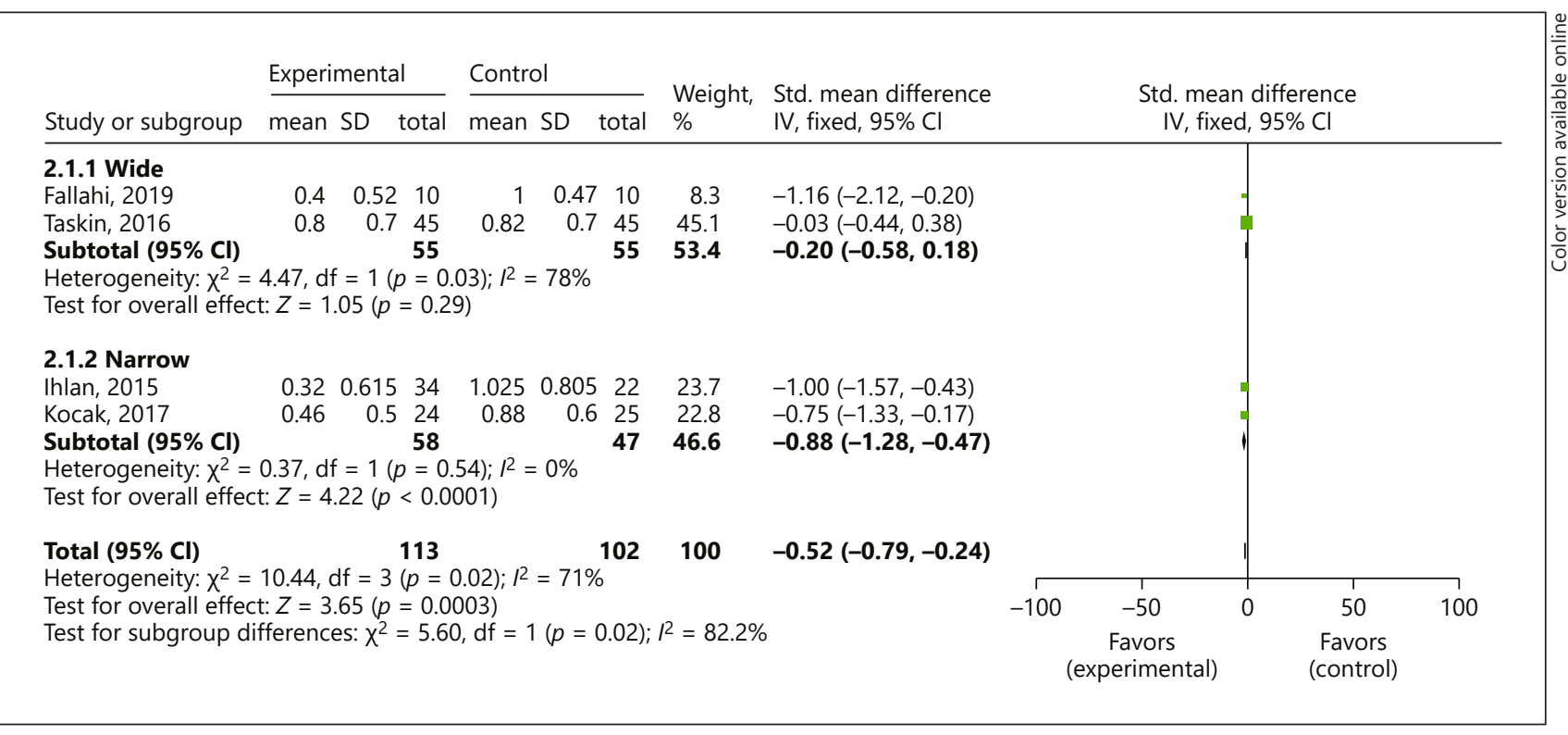

Fig. 11. Forest plot of standardized mean differences for the assessment of periorbital ecchymosis on postoperative day 7 considering the width of surgical incision.

$\left(\mathrm{SMD}=-0.89 ; \mathrm{CI}=-1.29,-0.48 ; I^{2}=0 \% ; p<0.0001 ;\right.$ Fig. 8). The SMD was higher in osteotomies with narrow incisions. Also in this group was heterogeneity insignificant.

The results were also similar for the postsurgical day 7. In particular, for patients that underwent lateral osteotomy with a wide surgical incision (SMD $=-0.32 ; \mathrm{CI}=-1.12,-0.49$; $I^{2}=63 \% ; p=0.44 ;$ Fig. 9), the SMD was lower than in patients that underwent narrow surgical incision (SMD $=-1.01 ; \mathrm{CI}=-2.34,-0.32 ; I^{2}=90 \% ; p=0,14 ;$ Fig. 9). However, heterogeneity was substantial in both groups. 
Tsikopoulos et al.: Piezoelectric or Conventional Osteotomy in Rhinoplasty?

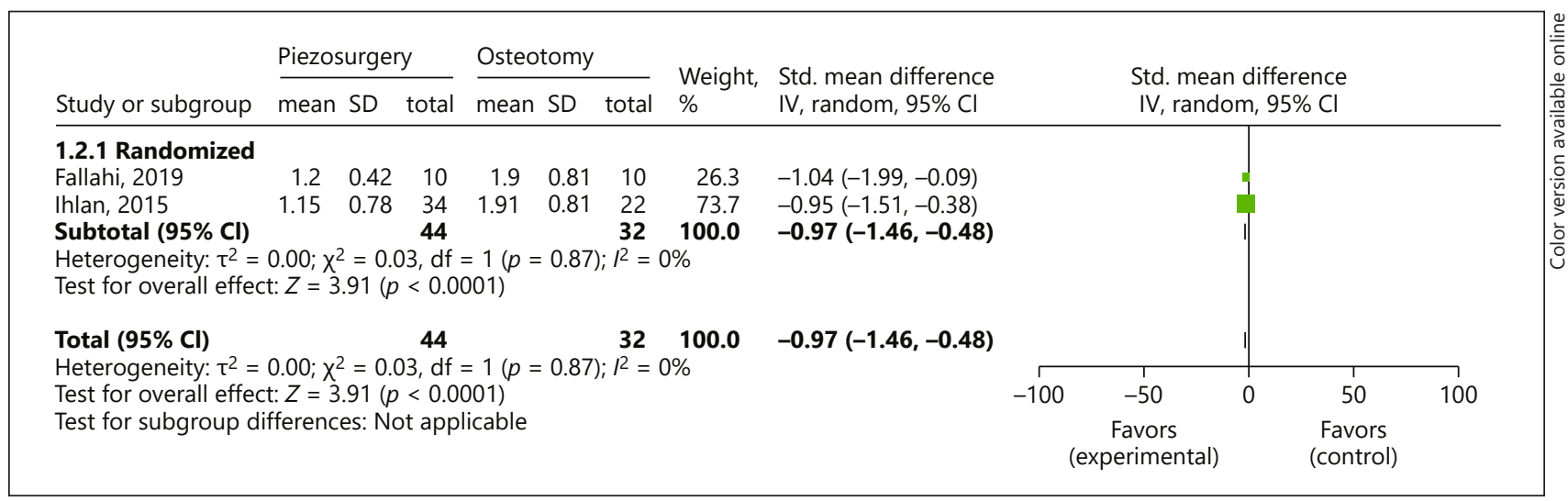

Fig. 12. Forest plot of standardized mean differences for the assessment of eyelid edema within the first 3 postoperative days (sensitivity analysis).

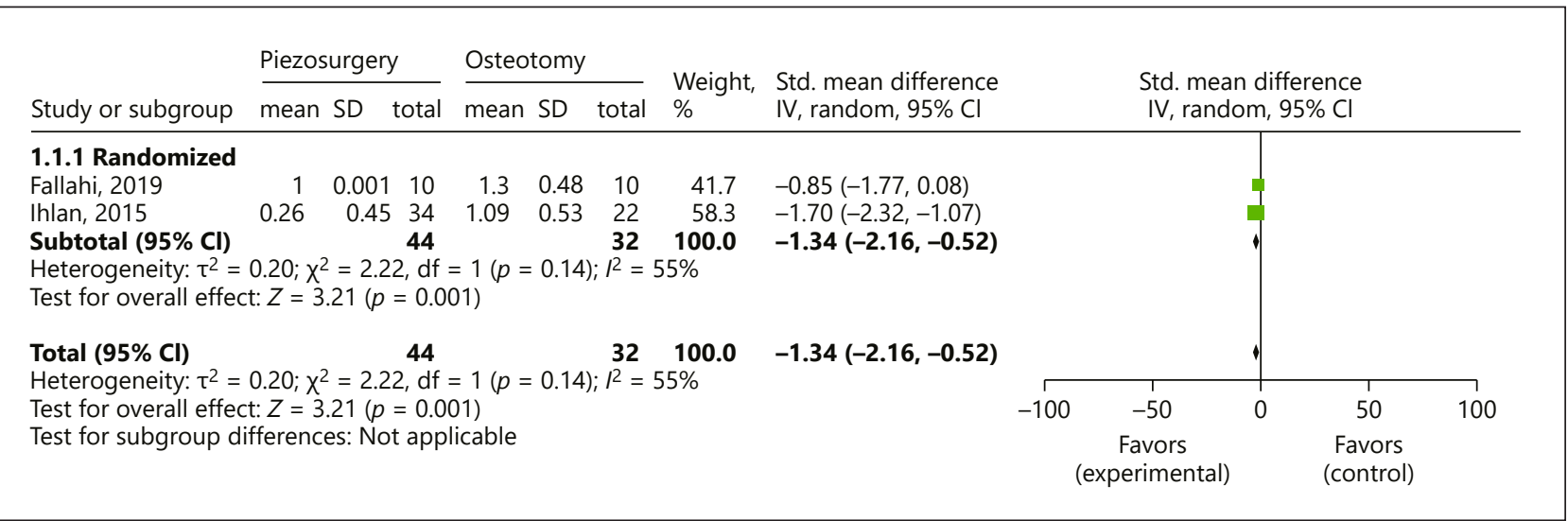

Fig. 13. Forest plot of standardized mean differences for the assessment of eyelid edema on postoperative day 7 (sensitivity analysis).

Similarly, periorbital ecchymosis was assessed within the first 3 postoperative days separately for patients that underwent lateral osteotomy with a wide surgical incision $\left(\mathrm{SMD}=-0.73 ; \mathrm{CI}=-1.96,0.50 ; I^{2}=81 \% ; p=0.24\right.$; Fig. 10$)$ as well as for those with a narrow surgical incision (SMD $=-1.04 ; \mathrm{CI}=-1.45,-0.62 ; I^{2}=0 \% ; p<0.0001$; Fig. 10). The SMD was higher in osteotomies with narrow incisions. Also in this group was heterogeneity insignificant.

The same assessment was done on the postsurgical day 7 separately for patients that underwent lateral osteotomy with a wide surgical incision $(\mathrm{SMD}=-0.20 ; \mathrm{CI}=-0.58,0.18$; $I^{2}=78 \% ; p=0.29$; Fig. 11) as well as for those with a narrow surgical incision (SMD = -0.88 ; CI $=-1.28,-0.47 ; I^{2}=0 \% ; p<0.0001$; Fig. 11). The SMD was higher in osteotomies with narrow incisions. Also in this group was heterogeneity insignificant.

\section{Sensitivity Analyses}

We conducted a predetermined sensitivity analysis in which trials of an unclear or high risk of bias were excluded, and insignificant heterogeneity levels were detected with the exception of the assessment of eyelid edema on postoperative day $7\left(I^{2}=55 \%\right)$. Statistical differences were detected between primary and sensitivity analysis when we accounted for periorbital ecchymosis and eyelid edema. 
Tsikopoulos et al.: Piezoelectric or Conventional Osteotomy in Rhinoplasty?

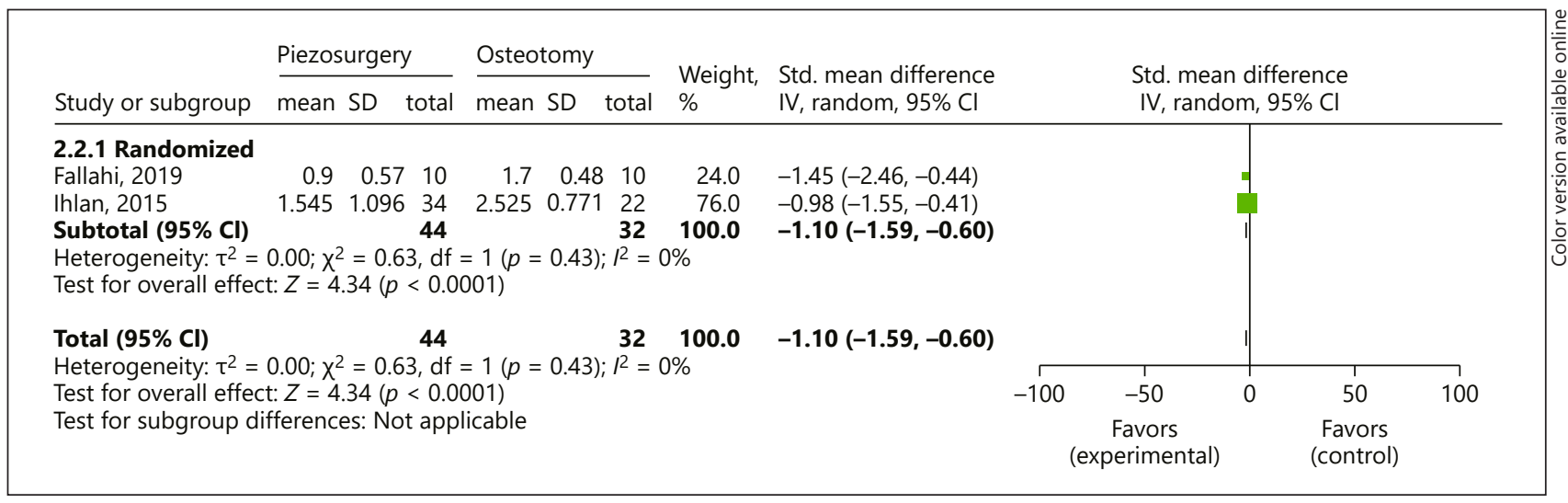

Fig. 14. Forest plot of standardized mean differences for the assessment of periorbital ecchymosis within the first 3 postoperative days (sensitivity analysis).

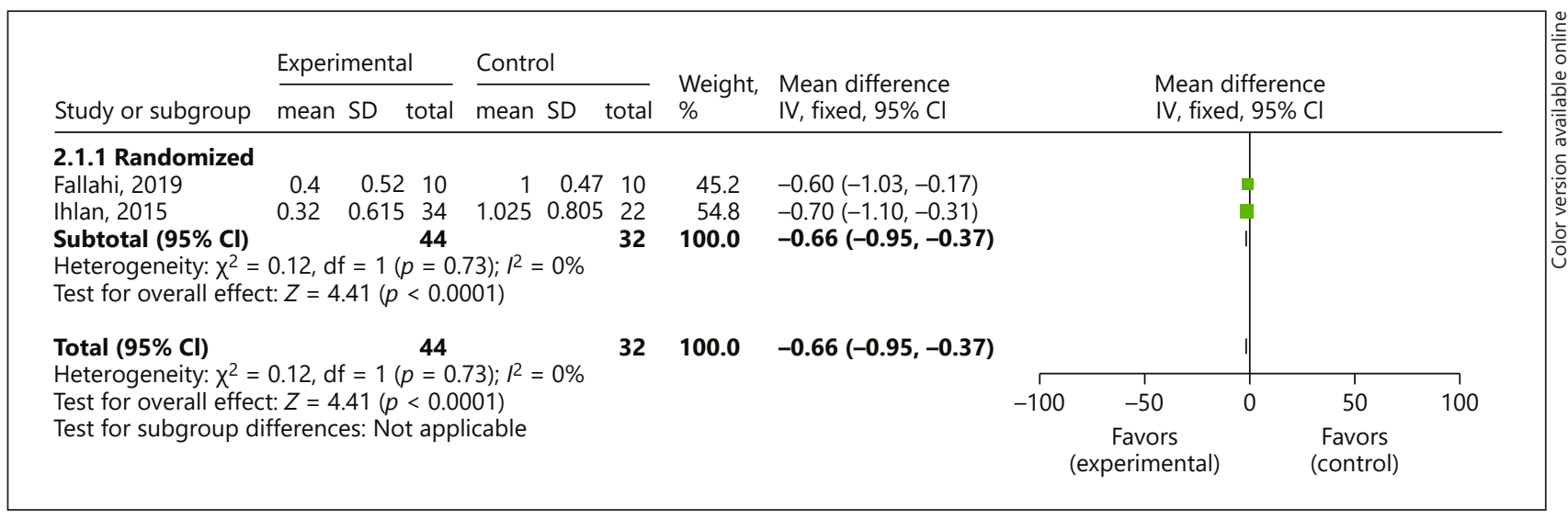

Fig. 15. Forest plot of standardized mean differences for the assessment of periorbital ecchymosis on postoperative day 7 (sensitivity analysis).

The SMD calculated after sensitivity analysis were higher in all outcomes in comparison with the primary analysis; thus, the differences in postoperative eyelid edema and periorbital ecchymosis between control and intervention groups were more marked for all outcomes.

Specifically, the results for eyelid edema within the first 3 postoperative days were: SMD $=-0.97 ; 95 \% \mathrm{CI}=-1.46,-0.48 ; p<0.0001 ; I^{2}=0 \%$ (Fig. 12); and on postoperative day 7 were: SMD $=-1.34 ; 95 \%$ CI $=-2.16,-0.52 ; p=0.001 ; I^{2}=55 \%$ (Fig. 13).

Accordingly, the results for periorbital ecchymosis within the first 3 postoperative days were: $\mathrm{SMD}=-1.10 ; 95 \% \mathrm{CI}=-1.59,-0.60 ; p<0.0001 ; I^{2}=0 \%$ (Fig. 14); and on postoperative day 7 were: SMD $=-0.66 ; 95 \% \mathrm{CI}=-0.95,-0.37 ; p<0.0001 ; I^{2}=0 \%$ (Fig. 15).

\section{Discussion}

Various studies show that soft tissue injury during osteotomies leads to postsurgical edema and ecchymosis [8, 27-28]. Surgical techniques and devices might have a role in these morbidities. Therefore, the ideal method and approach for lateral osteotomy is still unclear [29], and there is a great interest in potential osteotomy techniques and instruments to prevent soft-tissue injury [30]. In the current study, we compared the clinical outcomes of 
piezoelectric and conventional lateral osteotomies in rhinoplasty and we showed that piezoelectric osteotomies lead to less intraoperative and postoperative morbidities compared to conventional osteotomies.

Piezoelectric osteotomies were indeed associated with less periorbital ecchymosis and eyelid edema, not only during the first 3 postsurgical days but also on postsurgical day 7 . For eyelid edema, the effect size between the control and the intervention group was quite similar and was delineated as moderate on both the first 3 postoperative days and on postoperative day 7. Thus, eyelid edema was moderately and almost equally lower after piezoelectric osteotomies through the first postoperative week in comparison with conventional osteotomies. For periorbital ecchymosis, the significant difference was higher within the first 3 postoperative days than on postoperative day 7 and was characterized as large for the first 3 postoperative days and as moderate on postoperative day 7 . As a result, we conclude that especially regarding the first 3 postoperative days, lateral osteotomies in rhinoplasty which are conducted with piezotomes are connected with significantly less periorbital ecchymosis compared to conventional osteotomies. Additionally, patients that underwent piezoelectric osteotomy suffered from fewer intraoperative mucosal injuries. In particular, the control group had 16.67 higher relative odds of mucosal injury during the conventional osteotomies compared to the intervention group. These results confirm that piezoelectric osteotomies are much safer regarding intraoperative mucosal injuries and soft tissue damage in general compared to conventional osteotomies. Finally, patients that underwent piezoelectric lateral osteotomy during rhinoplasty experienced less postoperative pain within the first 3 postsurgical days in comparison with patients that underwent conventional osteotomies. The SMD between those groups of patients was quite high and was characterized as large. This proves as a result, that piezoelectric osteotomies cause less nerve damage and consequently less pain compared to conventional osteotomies.

Furthermore, in an attempt to minimize bias in our results, we conducted a predetermined sensitivity analysis in which trials of an unclear or high risk of bias were excluded. Statistical differences were detected between primary and sensitivity analysis when we accounted for periorbital ecchymosis and eyelid edema as the SMD calculated after sensitivity analysis were higher in all outcomes in comparison with the primary analysis. Thus, the sensitivity analysis further verified the differences in postoperative eyelid edema and periorbital ecchymosis between control and intervention groups and the benefits of executing lateral osteotomies in rhinoplasty with a piezotome. Undoubtedly, all those findings prove that piezosurgery could be the surgical method of choice for lateral osteotomies in rhinoplasties, either open or close.

One major issue we faced during the quantitative analysis was the significant heterogeneity of the outcomes regarding postoperative eyelid edema and ecchymosis. Therefore, we attempted a subgroup analysis taking into consideration differences in surgical approach, in order to minimize as possible heterogeneity of the outcomes. Generally, there has been great ambiguity regarding the favorable surgical approach (percutaneous or intranasal) of lateral osteotomy in rhinoplasty, depending not only on the aesthetic results but also on the intraoperative and postoperative morbidities. Various studies have attempted to compare those approaches without a clear result [15-21]. In our review, we included studies where both approaches were executed, but data exploitable for analysis came only from studies with internal osteotomies. Thus, the postsurgical results of the surgical approach performed (external or intranasal approach) could not be assessed. However, in our review we incorporated studies where lateral osteotomies were executed either with a wide surgical incision and thus under direct visualization of the procedure, or with a narrow surgical incision. Totally, 110 patients were subjected to lateral osteotomies with a wide surgical incision in both the control and the intervention groups and presented an undoubtedly lower difference 
regarding postoperative edema and ecchymosis for piezoelectric osteotomy under direct vision in comparison with the patients subjected to blind lateral osteotomies that were executed with a narrow surgical incision. Overall, those results indicate that piezoelectric lateral osteotomy in rhinoplasty is especially effective for osteotomies that are not performed under direct vision.

\section{Dealing with Clinical Diversity}

In the present study, we performed a comparison of postsurgical morbidities linked to the surgical technique chosen (piezoelectric or conventional osteotomy) using a pairwise meta-analysis study design. After analyzing data, we observed significant heterogeneity indicating that the intervention effects were significantly affected by clinical factors that varied across studies. Taking into consideration that the optimal surgical approach (intranasal or percutaneous osteotomy/blind or under direct vision osteotomy) is yet to be defined, this diversity could be attributed to the surgeon's preferences in terms of surgical approaches regarding the piezoelectric instrument for lateral osteotomy.

\section{Strengths and Limitations of the Present Systematic Review}

In this systematic review, sufficient sample size from 7 studies and 347 patients allowed safe conclusions on postoperative morbidities to be drawn, whether piezoelectric osteotomy is connected with fewer postoperative morbidities than conventional osteotomy in rhinoplasty. However, given the fact that most of the included trials were deemed to be at an unclear risk of bias, we recommend that more high-quality trials be conducted in the future in order to delineate this research area.

Furthermore, mid-term and long-term postsurgical results were not evaluated in the majority of the included studies. On top of that, patient-reported outcomes were not assessed in the above trials. Therefore, we advocate that long-term follow-ups be considered in future studies placing emphasis not only on clinician-oriented but also patient-assessed outcomes such as aesthetic results and patient satisfaction.

\section{Acknowledgment}

The authors would like to thank their teachers who inspired them to engage in the fascinating field of medical research.

\section{Statement of Ethics}

The published research complied with the guidelines for human studies and was conducted in accordance with the World Medical Association Declaration of Helsinki.

\section{Disclosure Statement}

The authors declare that they have no conflict of interest.

\section{Funding Sources}

The study was not supported by funding sources. 
Tsikopoulos et al.: Piezoelectric or Conventional Osteotomy in Rhinoplasty?

\section{Author Contributions}

This systematic review and meta-analysis was conducted as part of the Postgraduate Program "Research Methodology in Biomedicine, Biostatistics and Clinical Bioinformatics" of Medical School of Larissa of University of Thessaly, under the guidance of the co-author Konstantinos Tsikopoulos. The supervisor of the study was Chrysoula Doxani. Elias Zintzaras was the head of the Postergraduate Programme and Ioannis Stefanidis Head of the Medical Department of University of Thessaly. Both of them assisted the author with their comments during the performance of this study. Charalambos Skoulakis and Gabriele Meroni also contributed to this study with their guidance in scientific issues.

\section{References}

1 Becker DG, McLaughlin RB Jr, Loevner LA, Mang A. The lateral osteotomy in rhinoplasty: clinical and radiographic rationale for osteotome selection. Plast Reconstr Surg. 2000 Apr;105(5):1806-16.

2 Harshbarger RJ, Sullivan P: The optimal medial osteotomy: A study of nasal bone thickness and fracture patterns. Plast Reconstr Surg 2001 Dec;108(7):2114-9; discussion 2120-1.

3 Giacomarra V, Russolo M, Arnez ZM, Tirelli G. External osteotomy in rhinoplasty. Laryngoscope. 2001 Mar; 111(3):433-8

4 Manafi A, Eslami Shahr Babaki A, Mehrabani G, Shahlaee A, Manafi A. Can we add auricular composite graft to our rhinoplasty armamentarium? World J Plast Surg. 2013 Jan;2(1):33-40.

5 Goldfarb M, Gallups JM, Gerwin JM. Perforating osteotomies in rhinoplasty. Arch Otolaryngol Head Neck Surg. 1993 Jun;119(6):624-7.

6 Meller C, Havas TE. Piezoelectric technology in otolaryngology, and head and neck surgery: a review. J Laryngol Otol. 2017 Jul;131 S2:S12-8.

7 Rohrich RJ, Janis JE, Adams WP, Krueger JK. An update on the lateral nasal osteotomy in rhinoplasty: an anatomic endoscopic comparison of the external versus the internal approach. Plast Reconstr Surg. 2003 Jun; 111(7):2461-2.

8 Robiony M, Toro C, Costa F, Sembronio S, Polini F, Politi M. Piezosurgery: a new method for osteotomies in rhinoplasty. J Craniofac Surg. 2007 Sep;18(5):1098-100.

9 Gerbault O, Daniel RK, Kosins AM. The role of piezoelectric instrumentation in rhinoplasty surgery. Aesthet Surg J. 2016;36(1):21-34.

10 Labanca M, Azzola F, Vinci R, Rodella LF. Piezoelectric surgery: twenty years of use. Br J Oral Maxillofac Surg. 2008 Jun;46(4):265-9.

11 Pavlíková G, Foltán R, Horká M, Hanzelka T, Borunská H, Sedý J. Piezosurgery in oral and maxillofacial surgery. Int J Oral Maxillofac Surg. 2011 May;40(5):451-7.

12 Horton JE, Tarpley TM Jr, Wood LD. The healing of surgical defects in alveolar bone produced with ultrasonic instrumentation, chisel, and rotary bur. Oral Surg Oral Med Oral Pathol. 1975 Apr;39(4):536-46.

13 Sherman JA, Davies HT. Ultracision: The harmonic scalpel and its possible uses in maxillofacial surgery. Br ] Oral Maxillofac Surg. 2000;38:530-2.

14 Vercellotti T, Pollack AS. A new bone surgery device: Sinus grafting and periodontal surgery. Compend Contin Educ Dent. 2006;27(5):319-25.

15 Tirelli G, Tofanelli M, Bullo F, Bianchi M, Robiony M. External osteotomy in rhinoplasty: Piezosurgery vs osteotome. Am J Otolaryngol. 2015 Sep-Oct;36(5):666-71.

16 Ilhan AE, Cengiz B, Caypinar Eser B. Double-Blind Comparison of Ultrasonic and Conventional Osteotomy in Terms of Early Postoperative Edema and Ecchymosis. Aesthet Surg J. 2016;36(4):390-401.

17 Tașkın Ü. Batmaz T, Erdil M, Aydın S, Yücebaș K. The comparison of edema and ecchymosis after piezoelectric and conventional osteotomy in rhinoplasty. Eur Arch Otorhinolaryngol. 2017 Feb;274(2):861-865

18 Koçak I, Doğan R, Gökler 0. A comparison of piezosurgery with conventional techniques for internal osteotomy. Eur Arch Otorhinolaryngol. 2017 Jun;274(6):2483-2491.

19 Koc B, Koc EA, Erbek S. Comparison of Clinical Outcomes using a Piezosurgery Device Vs. A Conventional Osteotome for Lateral Osteotomy in Rhinoplasty. Ear Nose Throat J. 2017 Aug;96(8):318-326.

20 Ghavimi MA, Nezafati S, Yazdani J, Pourlak T, Amini M, Pourlak T, et al. Comparison of edema and ecchymosis in rhinoplasty candidates after lateral nasal osteotomy using piezosurgery and external osteotomy. J Adv Pharm Technol Res. 2018 Jul-Sep;9(3):73-79.

21 Fallahi HR, Keyhan SO, Fattahi T, Mohiti AK. Comparison of piezosurgery and conventional osteotomy post rhinoplasty morbidities: A double-blind randomized controlled trial. J Oral Maxillofac Surg. 2019 May;77(5): 1050-1055.

22 Kara CO, Gökalan I. Effects of single-dose steroid usage on edema, ecchymosis, and intraoperative bleeding in rhinoplasty. Plast Reconstr Surg. 1999 Dec;104(7):2213-8.

23 Higgins JP, Altman DG. Chapter 8: Assessing risk of bias in included studies. In: Higgins JPT, Green S, editors. Cochrane Handbook for Systematic Reviews of Interventions. Chichester: John Wiley \& Sons; 2008. 
24 The Nordic Cochrane Centre, The Cochrane Collaboration. Review Manager (RevMan). 5.1. Copenhagen: The Nordic Cochrane Centre, The Cochrane Collaboration; 2011.

25 Sterne JAC, Egger M, Moher D. Chapter 10: Addressing reporting biases. In: Higgins JPT, Green S, editors. Cochrane Handbook for Systematic Reviews of Interventions. Chichester: John Wiley \& Sons, 2008.

26 Cohen J. Statistical power analysis for the behavioral sciences. 2nd ed. Hillsdale: Lawrence Erlbaum Associates; 1988.

27 Thomas JR, Griner NR, Remmler DJ. Steps for a safer method of osteotomies in rhinoplasty. Laryngoscope. 1987 Jun;97(6):746-7.

28 Caglar E, Celebi S, Topak M, Develioglu NO, Yalcin E, Kulekci H. How can periorbital oedema and ecchymose be reduced in rhinoplasty? Eur Arch Otorhinolaryngol. 2016;273(9):2549-2554.

29 Yücel OT. Which type of osteotomy for edema and ecchymosis: external or internal? Ann Plast Surg. 2005 Dec; 55(6):587-90.

30 Nolst Trenité GJ. Trauma reduction in rhinoplastic surgery. Rhinology. 1991 Jun;29(2):111-6. 